\title{
DIAGNÓSTICO DAS CONDIÇÕES DE SANEAMENTO NA COMUNIDADE DO MACIÇO DO MORRO DA CRUZ - FLORIANÓPOLIS - SC - BRASIL
}

\section{DIAGNÓSTICO DE LAS CONDICIONES DE SANEAMIENTO EN LA COMUNIDAD DEL MACIZO ROCOSO DEL MONTE DE LA CRUZ - FLORIANÓPOLIS - SC - BRASIL}

\author{
M. Eng. Nora Alejandra Patrícia Rebollar ${ }^{1}$ \\ M. Eng. Fernanda Simoni Schuch ${ }^{2}$ \\ Prof. Dr. Carlos Loch ${ }^{3}$
}

Este artigo relata a experiência e apresenta os resultados obtidos no projeto 'Saneamento nas Comunidades do Maciço do Morro da Cruz - Promoção da Cidadania -Florianópolis - SC', financiado pelo Ministério das Cidades, Ministério da Educação e Cultura do Brasil. Neste trabalho, realizou-se o diagnóstico das condições de saneamento da comunidade do Alto da Caieira do Saco dos Limões e a capacitação dos cidadãos da localidade de forma a implementar uma política educacional. Esta capacitação se deu a partir da conscientização popular acerca da importância do saneamento básico, desenvolvendo juntamente com a comunidade, atividades para conscientizar os cidadãos quanto à necessidade de uma ocupação ordenada, em harmonia com áreas de preservação permanente. A comunidade está localizada em área considerada de preservação permanente segundo a legislação ambiental vigente. Em função de estar vivendo 'a margem da lei' em área de ocupação irregular, a população atualmente não tem acesso à água potável e sistema de esgoto fornecido pela concessionária estadual. Assim sendo, realizou-se um trabalho de campo para adquirir dados das residências tais quais: a existência ou não de reservatórios de água, fonte de captação da água utilizada, existência de sanitários, destinação do esgoto sanitário, entre outros. O diagnóstico final mostrou uma comunidade com problemas de abastecimento de água e esgoto favorecendo a proliferação de doenças em área que apresenta riscos em função de se localizar em áreas íngremes que foram desmatadas.

Palavras chave: saneamento, cidadania, abastecimento de água, capacitação.

Este artículo dice la experiencia y presenta los resultados conseguidos en el proyecto "saneamiento en las comunidades del Maciço del Morro de la Cruz promoción de la ciudadanía - Florianópolis - SC", financiado por el ministerio de las

\footnotetext{
1 noraarq@hotmail.com.br

2 fernandasimoni@yahoo.com.br

${ }^{3}$ loch@ecv.ufsc.br
} 
ciudades, el ministerio de la educación y la cultura del Brasil. En este trabajo, fue realizado un diagnosis de las condiciones del saneamiento de la comunidad del colmo del Caieira del Saco dos Limões y de la calificación de los ciudadanos del lugar de la forma para poner en ejecución una política educacional. Esta calificación se dio del conocimiento popular referente a la importancia del saneamiento básico, convirtiéndose junto con la comunidad, líneas de la dirección para una ocupación ordenada y balanceada, adentro armonía con áreas de la preservación permanente. La comunidad está situada, en área considerada de la preservación permanente según la legislación ambiental existente. En la función a vivir "el borde de la ley" en área de la ocupación irregular, la población no tiene el acceso a las aguas potables y sistema de la alcantarilla proveído para la concessionária del estado. Así siendo, un trabajo en el terreno fue convertido diagnosis para adquirir dado de las residencias tales que: la existencia o no de depósitos del agua, fuente del captación del agua usada, existencia sanitaria, destinación de la alcantarilla sanitaria, entre otras. La diagnosis final demostró a una comunidad con problemas del abastecimiento y de la alcantarilla de agua que favorecía la proliferación de enfermedades en el área en función de la cual presenta riesgos por localizase en las áreas escarpadas que deforested.

Llave de las palabras: saneamiento, ciudadanía, abastecimiento de agua, calificación

\section{INTRODUÇÃO}

No decorrer do ano de 2007 e 2008 foi realizado o diagnóstico das condições de abastecimento de água e esgoto das habitações da comunidade Alto da Caieira do Maciço do Morro da Cruz. Este trabalho foi financiado pelo Ministério das Cidades e Ministério da Educação e Cultura do governo brasileiro através do programa PROEXT2007. A execução ficou com a Universidade Federal de Santa Catarina através do Laboratório de Fotogrametria Sensoriamento Remoto e Geoprocessamento do Departamento de Engenharia Civil, coordenado pelo Prof. Dr. Carlos Loch.

Além do diagnóstico buscou-se capacitar os moradores quanto à utilização racional do uso da água e difundir informações para melhorar as condições de higiene. Este trabalho abrange um total de 1.500 moradores da comunidade.

$\mathrm{A}$ área de estudos está posicionada geograficamente entre as baías Norte e Sul da llha de Santa Catarina. Faz parte do que se denomina Maciço Central de Florianópolis ou do Morro da Cruz. Está localizada no distrito sede do município de Florianópolis como mostra a figura a seguir: 
Figura 01: Figura de Localização

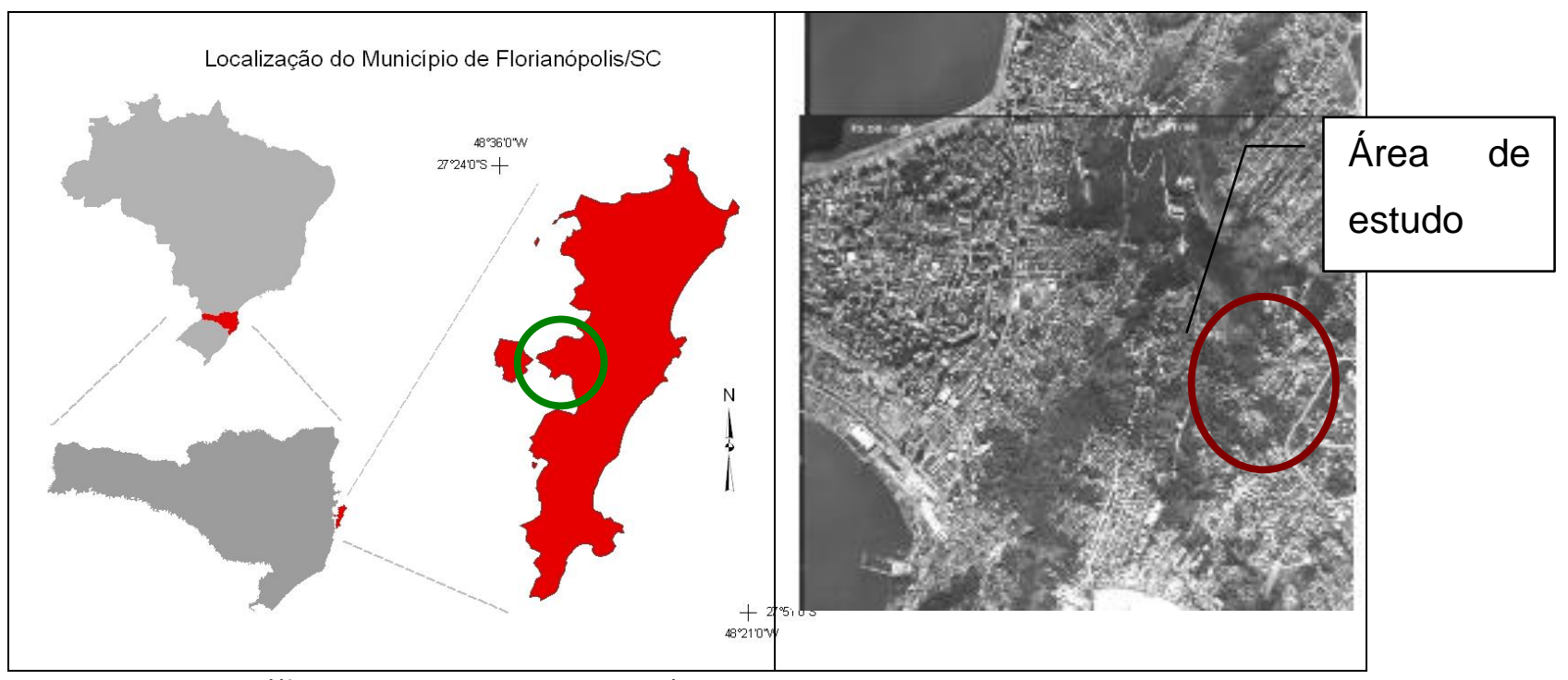

Fonte: http://floripa.geoguia.com.br/

A problemática abordada neste estudo vem a confirmar uma situação que há muito se conhece nas grandes cidades brasileiras: a falta de infra-estrutura básica em comunidades carentes das grandes cidades. A falta de água e, conseqüentemente, de rede de esgotamento são uma constante no dia a dia dos moradores sendo motivo de protestos e reinvidicações (CASAN, 2007).

\subsection{Histórico de ocupações irregulares no Brasil e o reflexo na Área de Estudo}

Para um melhor entendimento da problemática que envolve a área de estudo, é necessário abordar como se deu a ocupação desordenada dos morros no Brasil, que é uma realidade presente em muitos municípios brasileiros.

$\mathrm{Na}$ segunda metade do século XIX, ao falar de cortiços, os médicos higienistas mantinham a vista parcialmente voltada para o porto do Rio de Janeiro. Era o medo do desembarque da febre amarela. Tornou-se assim evidente aos poucos que os cortiços e epidemias de febre amarela eram indissociáveis. Era necessário intervir radicalmente na cidade para eliminar tais habitações coletivas e afastar do centro da capital as 'classes perigosas' que nele residiam. Iniciou-se assim o despejo dos moradores de cortiços do Rio de janeiro, Bahia e outros centros onde a febre amarela era detectada. Os moradores, geralmente escravos libertos, soldados chegados da guerra dos canudos, sem ter para onde ir, invadem os 
morros. Anuncia-se o fim da era dos cortiços e o inicia-se o século das favelas (CHALHOUB, 1996).

Em Florianópolis/SC não foi diferente. Sua ocupação remonta do início do século XX. Inicialmente a área foi ocupada por escravos recém libertos e, em seguida, pela população pobre que foi expulsa da área central da cidade em nome de um movimento sanitarista para a renovação urbana. Na década de 1940 porções da floresta ombrófila densa ali existente estavam desmatadas sob o argumento de minimizar as conseqüências trazidas pela malária o que facilitou as primeiras ocupações da área (SAITO, 2004).

Atualmente o Maciço Central do Morro da Cruz é ocupado essencialmente por população de baixa renda, em locais que, de acordo com o Código Florestal Brasileiro, consiste em Áreas de Preservação Permanente - APP. A comunidade objeto de estudo deste trabalho localiza-se na porção superior do Maciço Central, sobre área de APP e com infra-estrutura precária.

Nas últimas décadas a ocupação das áreas no entorno no Maciço do Morro da Cruz se intensificou. Entre os anos de 1966 e 2002 houve um incremento de 49\% de área urbanizada no Maciço. Entre 1992 e 2000 percebe-se um incremento significativo no bairro Alto da Caieira (área de estudo) e no bairro Serrinha (SAITO, 2004).

A Caieira do Saco dos Limões corresponde a uma área do Maciço, de extrema importância ecológica e relativamente vulnerável à degradação, esta informação pode ser comprovada pela análise das fotografias apresentadas a seguir. A área circulada nas fotografias corresponde à área de trabalho deste projeto. 
Figura 02: Evolução da ocupação da área por fotografias aéreas

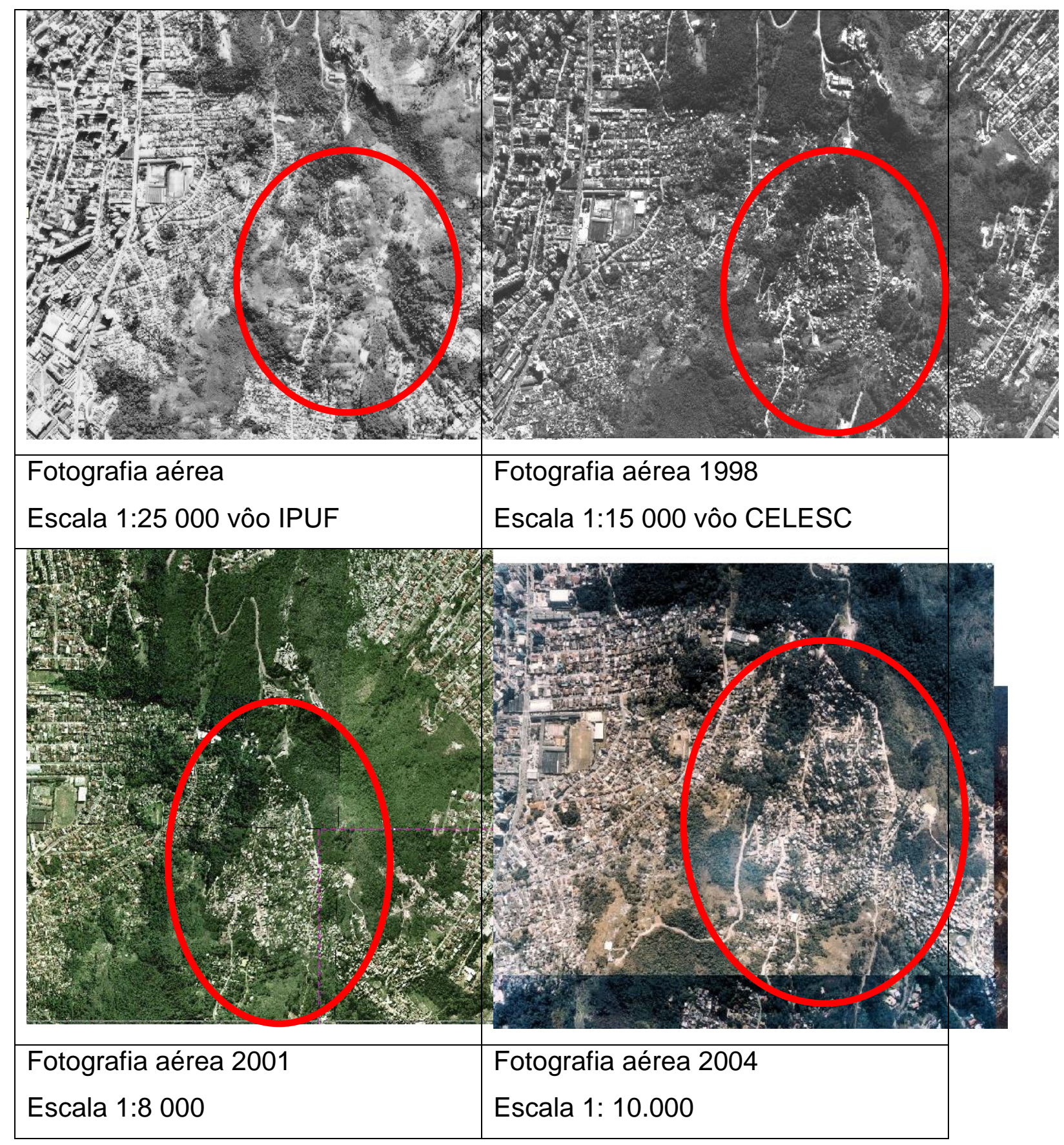

\section{METODO DO TRABALHO}

A partir das informações obtidas no estudo histórico de ocupação da área, foi elaborada uma planilha para cadastramento, de forma a se obter in loco dados sobre as condições de abastecimento de água na localidade. Nesta planilha constam campos a serem assinalados para coleta de informações em cada habitação tais 
como: existência de abastecimento de água, proveniência da água utilizada, existência ou não de vaso sanitário, entre outros.

Com o formulário em mãos, partiu-se para o levantamento dos dados em campo, na comunidade do Alto da Caieira. Vale salientar que em função das carências percebidas na comunidade, procurou-se evitar o uso de equipamento eletrônico para levantamento dos dados, buscando-se chegar mais à realidade local. Optou-se sim, pela utilização de pranchetas e formulários em papel, meios mais simples de aquisição dos dados.

Da mesma forma, para que esse trabalho fosse possível, procurou-se obter a anuência dos moradores, através de diálogos com líderes comunitários. Estabeleceram-se períodos do dia para que fosse possível a realização dos levantamentos. Uma vez que se trata de uma comunidade carente da presença do poder público, que convive com a presença do poder paralelo em função do tráfico de drogas.

Após o levantamento de dados, deu-se inicio ao processo de capacitação da população. A partir da constatação das condições locais, geraram-se cartilhas, folder e banners para a divulgação junto à comunidade quanto à importância do uso racional da água, da higiene pessoal e de formas alternativas para a coleta de água.

\section{RESULTADOS OBTIDOS}

Os resultados do cadastro realizado na comunidade foram tabulados em planilha eletrônica e podem ser traduzidos em números como mostram as figuras a seguir:

\subsection{Existências de Reservatórios e Fornecimento de Água Potável}

Segundo o gráfico abaixo aproximadamente $40 \%$ (quarenta por cento) das habitações não possuem reservatório de água e 1,2\% delas armazenam água em bombonas ou tambores. Estes valores perfazem um total de $41,4 \%$ de habitações sem reservação de água adequada. 
Figura 03: Gráfico de tipos reservatórios

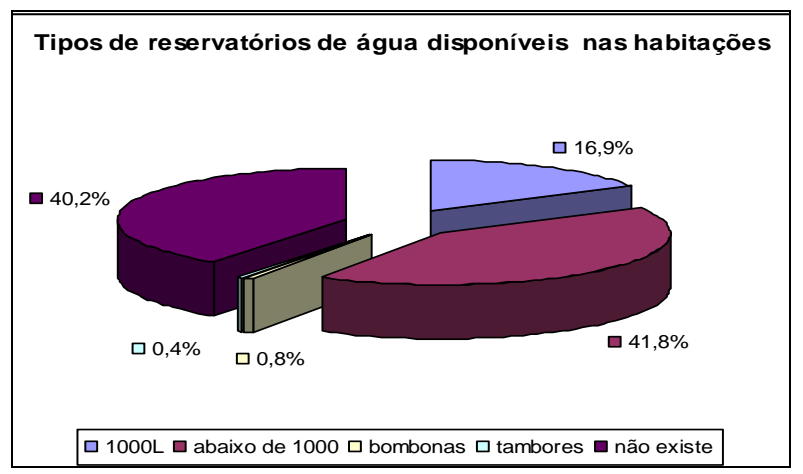

Por outro lado, quase $42 \%$ das habitações possuem algum reservatório com capacidade inferior a 1000 (mil) litros e 16,9\% possuem reservatório com capacidade de 1000 (mil) litros.

Figura 04: Abastecimento de água

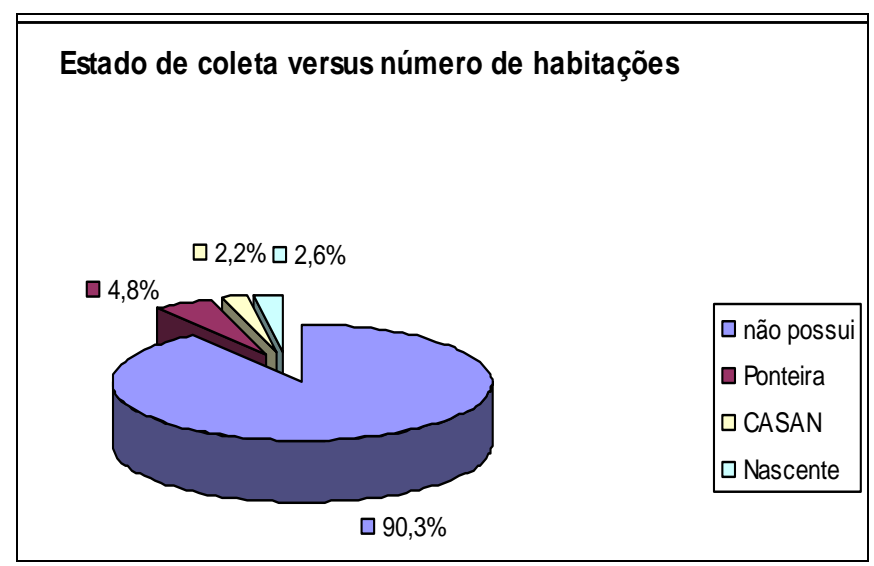

Confrontando-se os dados observa-se que, apesar de 41,4\% das habitações não possuírem reservatório de água, $90,3 \%$ dos entrevistados declararam não possuir uma fonte regular de coleta de água.

Apenas 2,2\% declarou possuir água da CASAN, concessionária de abastecimento de água e esgoto do Estado de Santa Catarina.

No entanto, percebe-se pelas instalações que a água utilizada pela comunidade é proveniente de apropriação indevida de pontos de abastecimentos legais.

Há moradores que se abastecem comprando de vizinhos que possuem vertentes em seus terrenos. Alguns fazem suas reservas em bombonas, tambores, bacias ou qualquer outro local onde a mesma possa ser armazenada. 


\subsection{Proveniência da água}

Os dados mostram que os moradores declararam não possuir fonte de abastecimento de água. Quando indagados a respeito da qualidade da água que consumiam, $88,9 \%$ dos entrevistados declararam que a água advinha da concessionária CASAN. 6,3\% declarou que a água que consomem não possui tratamento algum e 4,1\% não sabe informar sobre a qualidade da água que consome.

Figura 05: Proveniência da água

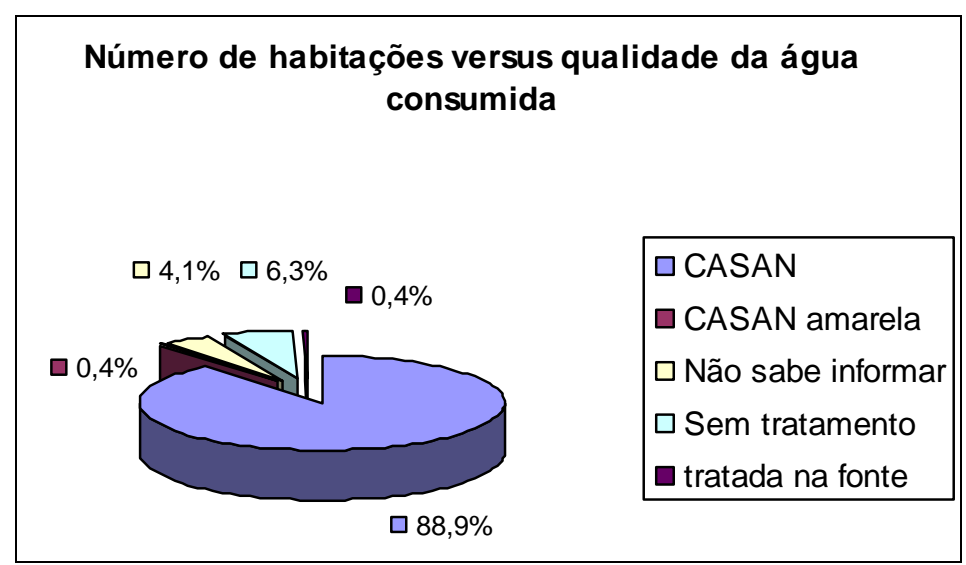

A água CASAN amarela significa que vem de apropriação ilegal. É tratada, mas a forma de armazenamento não condiz com as normas sanitárias de higiene.

\subsection{Existência de Sanitários}

Com relação à existência de vasos sanitários nas habitações, $77 \%$ dos entrevistados declarou possuir 1 (uma) unidade sanitária. Apenas 1\% declarou não possuir vaso sanitário em sua habitação e $22 \%$ declarou possuir 2 vasos sanitários. Aqueles que não possuem vaso sanitário declararam utilizar o recurso de latrinas rudimentares. 
Figura 06: Existência de vaso sanitário nas habitações

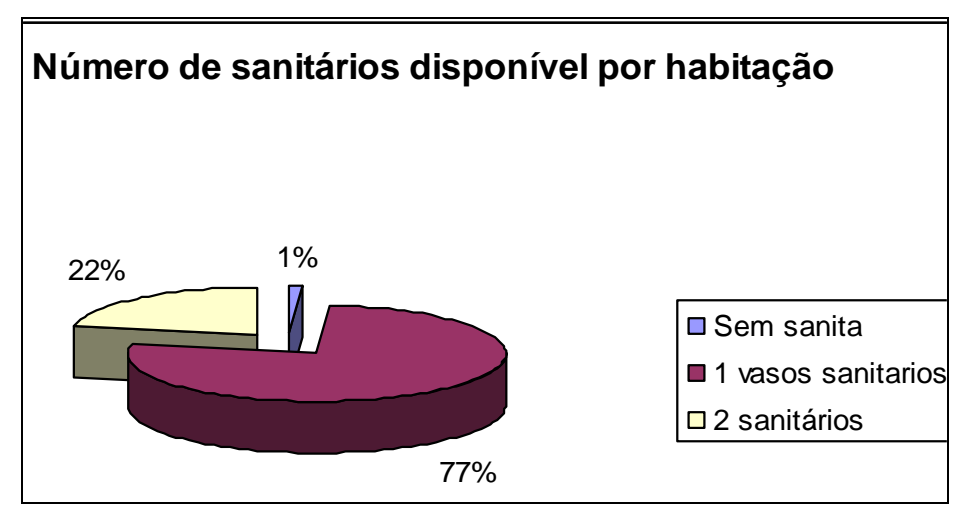

\subsection{Esgoto sanitário}

Segundo os dados coletados em campo, $91,1 \%$ dos casos existem fossa e sumidouro e apenas 2,2\% depositam dejetos em córregos ou aproveitam a água da chuva para se desfazer dos mesmos. $4,4 \%$ das habitações despejam seus resíduos na rua.

Figura 07: Despejo do esgotamento sanitário

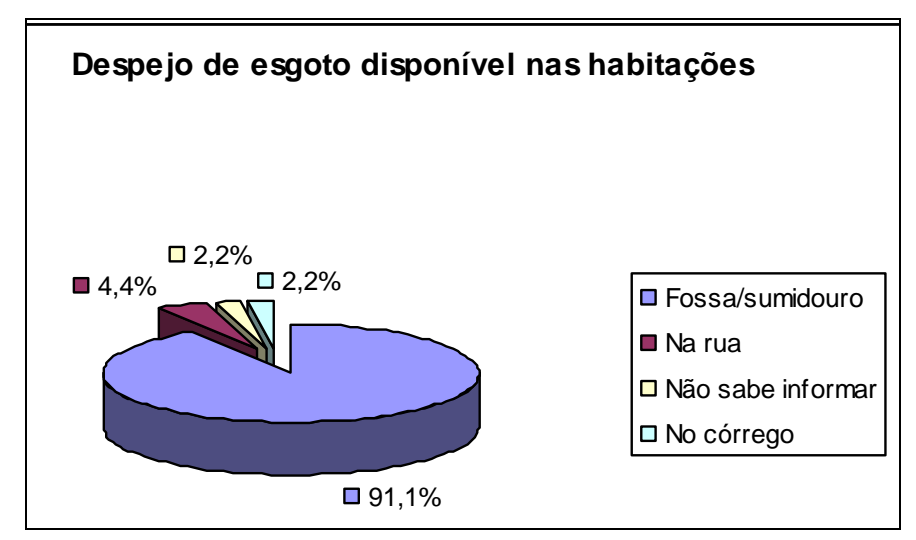

O alto índice de entrevistados que afirmou possuir fossa e/ou sumidouro para o esgotamento sanitário da habitação mostra que a população possui consciência da necessidade de uma destinação adequada para o esgoto doméstico.

\subsection{Capacitação}

A capacitação na comunidade se deu de duas formas: com a promoção de debates entre os profissionais da universidade envolvida no projeto e a comunidade, e através da visita do grupo de pesquisa aos moradores em suas habitações. 
Figura 08: Curso de capacitação na comunidade

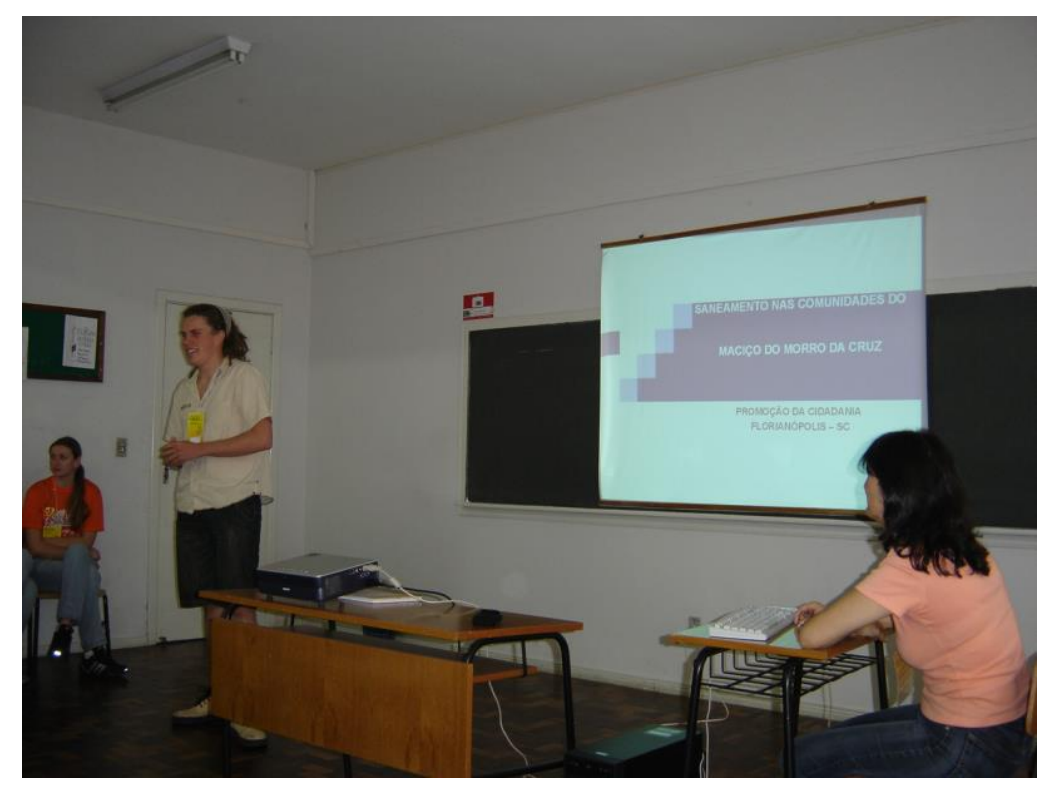

Nas visitas aos domicílios utiliza-se uma abordagem direta, de modo que fica estabelecida uma relação mais próxima às pessoas, e o diálogo entre as partes é mais facilitado. Em reuniões com um maior número de pessoas presente nem sempre se atinge o objetivo de envolver a todos os presentes fazendo-os participar do debate.

Foram distribuídos folders para auxiliar no processo educacional a que 0 projeto também se propunha como mostra a figura seguinte; 


\section{Figura 09: Frente e verso do folder distribuído na comunidade}

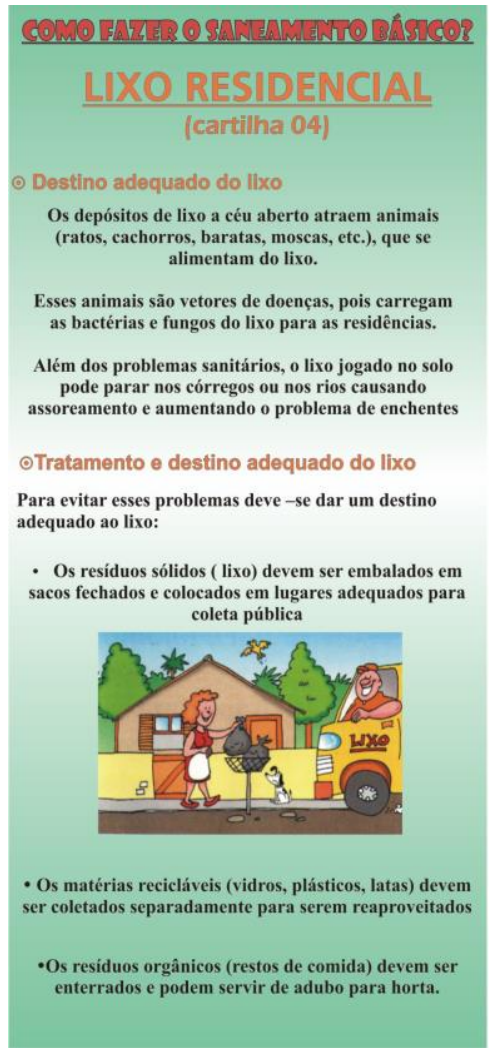

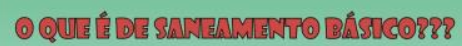

É um conjunto de cuidados importantes para proteger a saúde das pessoas. Todas as famílias única família pode prejudicar as outras.

\section{POR QUT FAL Básico?}

O saneamento básico é importante porque torna o meio ambiente mais saudável para as pessoas. $O$ saneamento previne doenças tais como verminose, hepatite, problemas de pele, tifo, dengue, desinteria muitas outras. Através do esgoto podem ser

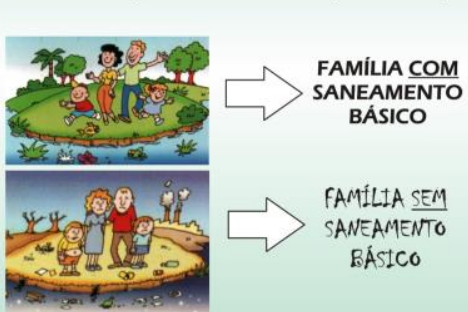

\section{QUAS SAొO ESSES GUDDDOS?}

-Proteger as fontes de água, os rios e matas próximo aos córregos

-Consumir somente água limpa (sem contaminação) -Destinar adequadamente o esgoto doméstico

$$
\text { -Destinar adequadamente o lixo }
$$

-Zelar pela higiene do corpo, da alimentação e da habitaçäo

Destinar adequadamente os dejetos animais
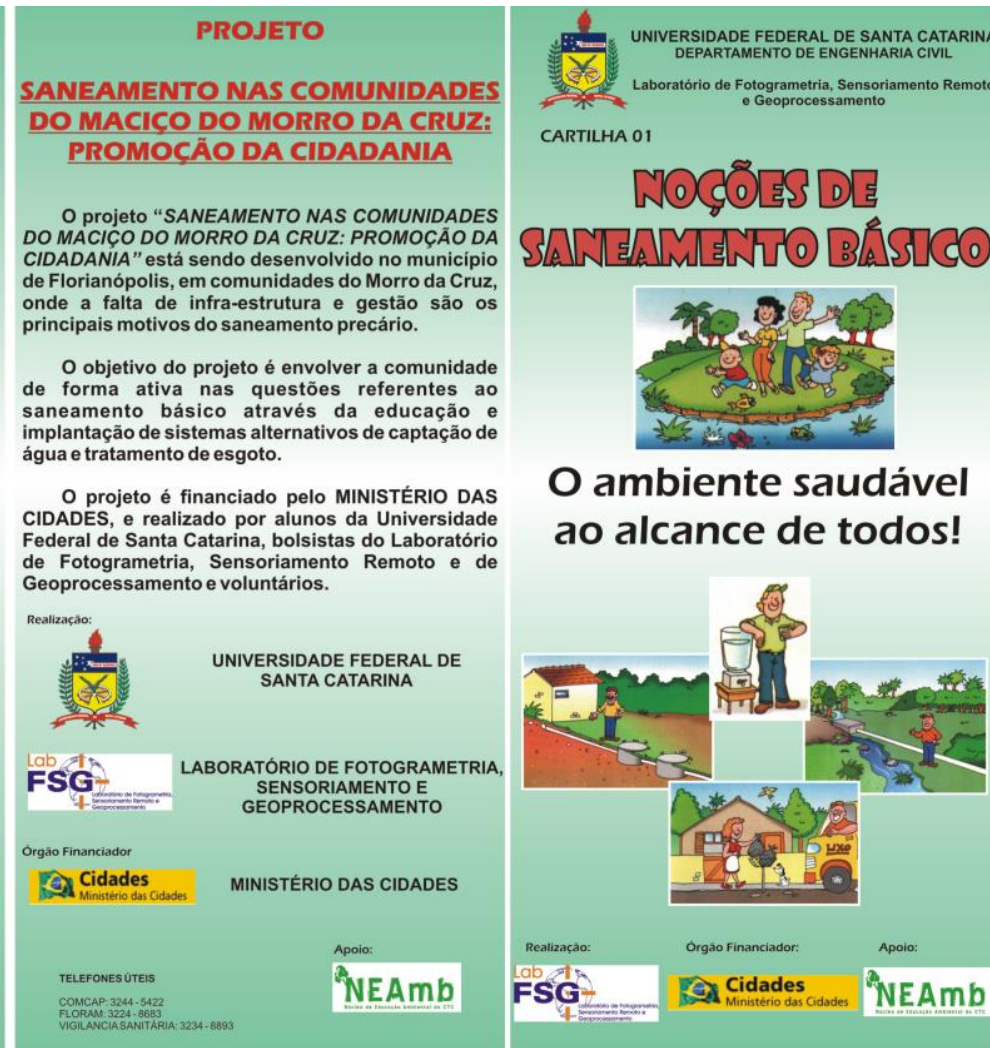

CARTILHA 01

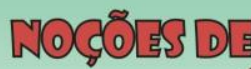

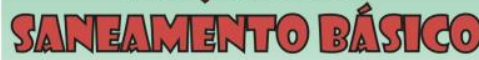

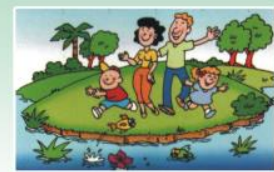

\section{O ambiente saudável ao alcance de todos!}

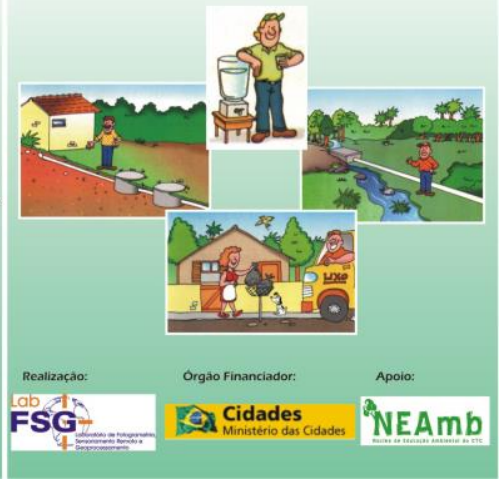

COMO FAL

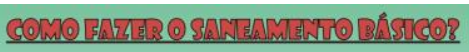

ÁGUA (cartillha 02)

- Proteçăo e tratamento da água para consumo

Como vimos anteriormente, a água

contaminada é causadora de muitas doenças. Por isso, devemos proteger as fontes de água contaminação e, se necessário, realizar tratamento da água.

As principais fontes de contaminação da água o osgoto doméstico, os dejetos animais,

๑ Como evitar a contaminaçăo da água

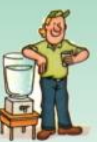

- Proteger as fontes e nascentes com mata próximo a rios córregos e nascentes

- Evitar o contato de animais com as fontes de água

- Manter limpos e protegidos os poços e caixas d'água - Destinar os esgotos domésticos para tratamento, longe de nascentes, poços ou rios

- Destinar adequadamente os dejetos animais (esterqueiras).

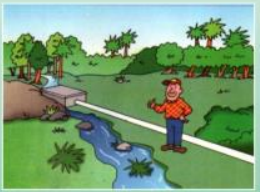

A água deve ser tratada antes de ser consumida. Existem várias formas de eliminar a contaminaç̃ da água. As mais comuns são a fervura, a filtragem a cloração.
ESGOTO SANITÁRIO

(cartilha 03)

○ 0 esgoto a céu aberto é um grande foco de doenças.

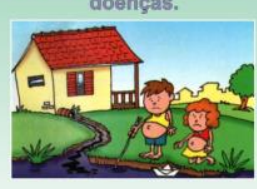

esgoto doméstico não pode ser jogado sem tratamento no solo ou nos rios, pois causam a contaminação e principalmente por:

- Consumo de água contaminada por esgoto - Consumo de alimentos contaminados

- Contato com a pele com o esgoto, água ou solo

Insetos ou roedores ( picada, mordida, urina, etc.)

-Tratamento e destino adequado do esgoto doméstico

Existem várias formas de tratamento do esgoto os sistemas de fossa filtro, e o tratamento biológico por zona de raizes.

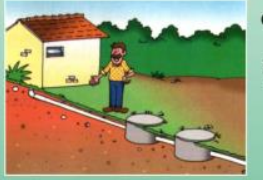

sistema de fossa e filtr elimina até $70 \%$ da poluị̧ão, enquanto que o tratamento por zona de quase toda a poluição. 


\section{CONCLUSÕES}

De um modo geral pode-se dizer que a comunidade do Alto da Caieira pertencente ao Maciço do Morro da Cruz possui uma situação precária quanto ao abastecimento de água.

Esta situação é configurada a partir dos dados levantados em campo que mostram uma comunidade com aproximadamente $40 \%$ das habitações sem reservatório de água e quase $90 \%$ utilizam água da CASAN, concessionária de água estadual, porém, obtida por meio de ligações clandestinas.

Cerca de $91 \%$ dos entrevistados declarou possuir fossa e sumidouro para despejar os dejetos, esse dado por si só aparenta mostrar consciência da população quanto à destinação dos dejetos humanos, no entanto, vale lembrar que estamos trabalhando com uma população assentada sobre área desprovida de infra-estrutura urbana. Isso quer dizer que, provavelmente, teremos o despejo de esgotamento sanitário como vilão da contaminação do lençol freático e das nascentes de água existentes no local. Nascentes estas que $2,6 \%$ dos habitantes do local utilizam para consumo de água.

Ao final pode-se concluir que o cadastramento das habitações é de suma importância para que se possa constatar e contribuir para identificar, diagnosticar e sugerir uma intervenção na área de estudo.

O diagnóstico obtido pela manipulação dos dados do levantamento mostra a realidade da população que vive em situação precária com deficiências quanto ao saneamento básico. E esta comunidade não é um caso isolado. Como esta, no Brasil, existem muitas outras que, pelo fato de viverem à margem da sociedade, não dispõem de condições mínimas de abastecimento de água e esgoto.

Estas comunidades possuem ainda questões sociais bem peculiares como a presença constante do poder paralelo que existe em áreas carentes em função do tráfico de drogas. Este talvez tenha sido um dos maiores desafios neste projeto, pois, desde o levantamento dos dados à realização das palestras e distribuição dos folders, tudo necessitava de um agendamento prévio com os líderes comunitários e as atividades tinham que ser desenvolvidas nos horários acordados com os mesmos.

O fato é que, na medida em que áreas de preservação em grandes centros urbanos não podem ser ocupadas legalmente, a ocupação ilegal acontece. A 
população que reside nestes espaços passa a demandar uma infra-estrutura que não pode ser atendida legalmente pelos órgãos competentes. Fica então o questionamento: que práticas adotar para que a população que reside nestas áreas obtenha a infra-estrutura necessária de modo que tal fato não comprometa o meio ambiente através da supressão da cobertura vegetal e do comprometimento das águas subterrâneas?

O governo brasileiro, no intuito de trazer condições dignas de moradia à essas populações, vêm desenvolvendo projetos para reestruturar essas comunidades, implantando a infra-estrutura necessária para uma melhoria nas condições de saneamento, transporte, saúde, etc. Essa melhoria se dá pela reurbanização das áreas com a abertura e calçamento de ruas, fornecimento de energia elétrica, etc.

No entanto, se refletimos isto significa que estamos ratificando uma ocupação em áreas que, pela legislação ambiental deveriam ser de floresta? Não estamos dizendo, com isto, que a população deve ser 'castigada' por não ter condições de viver em local apropriado, mas o fato é que, ao se priorizar o atendimento a essas famílias se coloca de lado outras questões que também são importantes para a sociedade como um todo.

O questionamento então continua. Como conciliar as duas temáticas: a preservação das florestas, tão necessárias à sustentabilidade ecológica, e o suprimento das carências básicas de uma população marginalizada em função de um modelo econômico há muito implantado? Qual o futuro que desejamos? Como o presente pode nos encaminhar a ele?

\section{REFERÊNCIAS}

AFONSO, Sônia. Urbanização de Encostas crises e possibilidades: o Morro da Cruz como um referencial de projeto de arquitetura de paisagem. 1999. Tese (Doutorado em Arquitetura) - Departamento de Arquitetura e Urbanismo, Faculdade de Arquitetura e Urbanismo da Universidade de São Paulo, São Paulo,

CAMPOS FILHO, C. M. Cidades Brasileiras, seu controle ou o caos. São Paulo: Editora Nobel, 1989.

CASAN, Companhia Catarinense de Águas e Saneamento, http://www.casan.com.br/index.php?sys=67\&id=170. Acesso em: 22 mar. 2009. 
CHALHOUB, Sidney. Cidade Febril - Cortiços e Epidemias na Corte Imperial. São Paulo, Companhia das Letras 1996.

MASCARÓ, Juan L.; YOSHINAGA, Mário. Infra-estrutura urbana. Porto Alegre: Editora Masquatro, 2005.

SAITO, S. Estudo Analítico da Suscetibilidade a Escorregamentos e quedas de blocos no maciço central de Florianópolis-SC. 2004. Dissertação (Mestrado em Geografia) - Departamento do Curso de Pós-Graduação em Geografia da Universidade Federal de Santa Catarina, Florianópolis. 